\title{
GMR
}

\section{A 425 T>C polymorphism in complement C7 association with resistance to Aeromonas hydrophila in grass carp}

\author{
Y.B. Shen', J.B. Zhang', J.J. Fu' ${ }^{1}$, X.Y. Xu', J.L. Li ${ }^{1,2}$, R.Q. Wang ${ }^{3}$ and Y.F. Xuan ${ }^{3}$ \\ ${ }^{1}$ Key Laboratory of Exploration and Utilization of Aquatic Genetic Resources, \\ Shanghai Ocean University, Ministry of Education, Shanghai, China \\ ${ }^{2} \mathrm{E}-$ Institute of Shanghai Universities, Shanghai Ocean University, Shanghai, China \\ ${ }^{3}$ Key Laboratory of Conventional Freshwater Fish Breeding and Health Culture \\ Technology Germplasm Resources, Ministry of Agriculture, \\ Suzhou Wujiang Area Aquaculture Limited Company, Suzhou, China \\ Corresponding author: J.L. Li \\ E-mail: jlli@shou.edu.cn \\ Genet. Mol. Res. 15 (1): gmr.15014526 \\ Received August 24, 2015 \\ Accepted November 17, 2015 \\ Published March 18, 2016 \\ DOI http://dx.doi.org/10.4238/gmr.15014526
}

\begin{abstract}
Aeromonas hydrophila, a widespread bacterium in the aquatic environment, causes hemorrhagic septicemia in fish. In the last decade, the disease has caused mass mortalities and tremendous economic loss in cultured fish. The complement component $\mathrm{C} 7$ is a terminal component of complement that interacts in a sequence of polymerization reactions with other terminal complement components to form a membrane attack complex. The formation of the membrane attack complex creates a pore in the membranes of certain pathogen that can lead to their death. The objective of this study was to identify single nucleotide polymorphisms (SNPs) in the C7 gene and to assess their association with $A$. hydrophila resistance in grass carp. A resource population consisting of 186 susceptible and 191 resistant grass carp was constructed. We sequenced a total of 7826 bp of the $\mathrm{C} 7$ gene and identified 6 SNPs that were genotyped in the resource population. The SNP $-1575 \mathrm{~A}>\mathrm{C}$ was positioned in the promoter
\end{abstract}


region of the gene. The SNP $425 \mathrm{C}>\mathrm{T}$ identified in the coding exon was a synonymous substitution in the fourth exon. Statistical analysis showed that SNP $425 \mathrm{C}>\mathrm{T}$ was associated with the incidence of hemorrhagic septicemia. The SNPs $-1575 \mathrm{~A}>\mathrm{C},-688 \mathrm{~T}>\mathrm{C}$, and $-266 \mathrm{~A}>\mathrm{C}$ were highly linked together $\left(r^{2}>0.85\right)$. No haplotypes generated with these 3 SNPs were associated with resistance to $A$. hydrophila in grass carp. These findings suggest that the $425 \mathrm{C}>\mathrm{T}$ polymorphism in $\mathrm{C} 7$ gene may be a significant molecular marker for resistance to $A$. hydrophila in grass carp.

Key words: Aeromonas hydrophila; Association analysis; Complement component C7; Grass carp; Single nucleotide polymorphism

\section{INTRODUCTION}

Grass carp (Ctenopharyngodon idella) is one of the most popular freshwater food fish species worldwide because of its desirable flavor and economic importance. Grass carp have been extensively cultivated in ponds as food fish since the 10th century in China (Cai, 1991). According to the Food and Agriculture Organization, its production reached 4.3 million tons in 2010 and is the 3rd largest contributor to the world's aquaculture production (FAO, 2012). However, the development of grass carp aquaculture has been seriously affected by disease. Mortalities of bacterial etiology are the most important cause of economic losses in grass carp culture. Aeromonas hydrophila is a Gram-negative bacterium, exists in all inland water environments, benthic sediments, and water organisms, and is a part of the normal intestinal microflora of healthy fish (Zhang et al., 2000). The bacterium causes bacterial septicemia and is associated with surface ulcerations in fish. The spread of infection occurs from direct contact with sick fish or environmental contamination.

This bacterium is typically controlled by fish farmers using wide range of antibiotics such as terramycin and florfenicol. However, while application of antibiotic treatment is an effective method for preventing bacterial diseases, it may be detrimental to the environment and human health (Cao et al., 2012). It also may lead to the development of antibiotic-resistant bacteria. Thus, enhancing fish resistance against diseases through selective breeding is necessary. Resistance to $A$. hydrophila in fish is known to be heritable, with heritability estimates ranging from 0.03-0.39 (Mahapatra et al., 2008; Ødegård et al., 2010). Differences in susceptibility have also been observed among different individual fish (Mahapatra et al., 2008; Crumlish et al., 2010). Hence, breeding for increased resistance to $A$. hydrophila is expected to be effective, particularly in combination with the high fecundity of both males and females.

The complement system, which is a chief component of innate immunity, is comprised of approximately 35 individual proteins (Holland and Lambris, 2002). Recognition of bacteria by complement components likely induces activation of 3 complement pathways, the classical, lectin, and alternative pathways. All 3 pathways result in the formation of a C3 convertase and generation of complement activation products triggering diverse biological activities, such as opsonization, endocytosis, cytolysis, and inflammation, resulting in the elimination of pathogenic microorganisms (Carroll and Sim, 2011). C7 is a terminal component of the complement that interacts in a sequence of polymerization reactions with other terminal complement components (C6, C8, and C9) to form a membrane attack complex (MAC) (DiScipio et al., 1988). The formation of the MAC creates a pore in membranes of a specific pathogen that can lead to its death. Insertion of the complement 
component $\mathrm{C} 7$ into the cell membranes is critical for the formation of the MAC. Thus, deficiencies in C7 may affect the formation of MAC and lytic activity of the cell (Hobart et al., 1995). C7 was first identified in human (DiScipio and Gagnon, 1982). Few studies have examined the association between genetic polymorphisms in C7 and disease traits (Nishimukai et al., 1989; Lian et al., 2012). The grass carp $C 7$ consists of 821 amino acids and is located on linage group 3 (Shen $\mathrm{YB}, \mathrm{Xu} \mathrm{XY}$ and $\mathrm{Li} \mathrm{JL}$, unpublished results). This gene contains 18 exons and 17 introns and is strongly expressed in the liver, head kidney, and trunk kidney (Shen et al., 2012). Transcriptional analyses showed that this gene was significantly induced in grass carp against $A$. hydrophila infection compared to control fish (Shen et al., 2012). However, the associations between genetic polymorphisms in $\mathrm{C} 7$ and resistance to bacterial disease remain unclear. The objective of the present study was to examine whether single nucleotide polymorphisms (SNPs) in the complement $\mathrm{C} 7$ are associated with $A$. hydrophila resistance in grass carp.

\section{MATERIAL AND METHODS}

\section{Grass carp populations}

One hundred and sixty grass carp parents from 5 wild populations and 1 cultured population were collected from 2007-2011 (Liu et al., 2009) for grass carp breeding. The 5 wild populations were Hanjiang (HJ), Jiujiang (JJ), Shishou (SS), Zhujiang River (ZJ), and Heilongjiang River (HLJ), and the cultured population (WJ) was from Wujiang, Jiangsu Province. Thirty individuals, taken randomly from 3 populations: WJ, ZJ, and HLJ (10 from each), were collected for resequencing of the complement component $\mathrm{C} 7$ and identification of SNPs.

A base population was constructed from 3 wild populations ( $\mathrm{HJ}, \mathrm{JJ}$, and SS) and 1 cultured population (WJ). G1 offspring were produced using part factorial cross and were cultured in the same pond. For the bacterial challenge experiment, 12001 -month-old juveniles were randomly selected and divided into 2 groups (600 in each group). These fish were transported to a large tank 2 weeks before the experiment. The fish were maintained in the 2 large tanks and were fed twice daily with pelleted feed. One group was exposed to A. hydrophila S2 (Aquatic Pathogen Collection Center of Ministry of Agriculture, China) $\left(7.0 \times 10^{7} \mathrm{CFU} / \mathrm{mL}\right)$ with aeration, while another group was cultured as a control group. Mortality was monitored for 21 days. Soon after mortality, the whole fish body was collected and stored in 95\% ethanol for genetic analysis. After 21 days, the surviving fish were euthanized in $20 \%$ buffered MS222 and whole fish bodies were collected for analysis. Genomic DNA was extracted using a standard phenol-chloroform method (Shen et al., 2013) and stored at $-20^{\circ} \mathrm{C}$.

\section{SNP identification and genotyping}

All SNPs were identified by sequencing of the whole genome using12 pairs of primers (Table 1). Sequencing primers were designed using Primer Premier 5.0 based on the $\mathrm{C} 7$ genomic DNA sequence (Shen et al., 2012). Genomic DNA was extracted from fin clips of 30 individuals from the WJ, ZJ, and HLJ populations. The size of amplified products ranged from 527-763 base pairs (bp). PCR products were purified and directly sequenced in both the $5^{\prime}$ and 3 ' directions using gene-specific primers with ABI 3730XL sequencers (Applied Biosystems, Foster City, CA, USA). Sequence alignment and SNP discovery were conducted using Sequencher 4.0 (GeneCodes Corporation, Ann Arbor, MI, USA). 


\begin{tabular}{|c|c|c|c|}
\hline Primers & Sequence of primer $\left(5^{\prime}-3^{\prime}\right)$ & Application & Product (bp) \\
\hline C7F1 & GGTGCCTTCATTTCAACATTTATTT & Promoter & \\
\hline C7R1 & GTGGAACACACAGACCTCTGTCTTC & & 743 \\
\hline C7F2 & AACACTATTTCAAAACCСТCСТTAC & 5'UTR and intron 1 & \\
\hline C7R2 & TTCAATTAGTTGCAACATTTCTCAT & & 597 \\
\hline C7F3 & GAAAAAATGGTAGAAAGTGCAACGC & Intron 1 & \\
\hline C7R3 & ATCAAATTACAACAAAGCAGGAGGG & & 527 \\
\hline C7F4 & CTTTGTTGTAATTTGATGATTTTTG & Intron 1 & \\
\hline C7R4 & GTTTTAGTACTTTTGTTGGGTTTTG & & 545 \\
\hline C7F5 & TGAAATGACAAAACCCAACAAAAGT & Exon 2-4 and intron & \\
\hline C7F5 & ATAAACAAACCAGCAATGAAAACTG & $2-4$ & 639 \\
\hline C7F6 & CAGTTTTCATTGCTGGTTTGTTTAT & Exon 5 and intron 5 & \\
\hline C7R6 & TATTAGGTTGCTGCATTGCATTATT & & 757 \\
\hline C7F7 & TAGGTTTGATGTGTTGACGGGTGAG & Exon $6-8$ and intron & \\
\hline C7R7 & AACGCTGTATAAAGGATCGATAGGC & 6,7 & 615 \\
\hline C7F8 & GTATGTGTTAACTTCCCTTTTTCTC & Exon 9 and intron 9 & \\
\hline C7R8 & TTTTACTGGCATCTTATGATTTTTG & & 695 \\
\hline C7F9 & GGACATACTGCTTATATCGCTGGCC & Exon 10,11 and intron & \\
\hline C7R9 & GAATCAACATCTGAATCACTTACTG & 10,11 & 611 \\
\hline C7F10 & CAGATGTTGATTCGTTCTGGTTCGT & Exon 12,13 and intron & \\
\hline C7R10 & TGCCTGTTGCAAGTTGTGTGTTGAT & 12,13 & 575 \\
\hline C7F11 & GGGAGAAAATTGAGGGGCGTGGGAA & Exon 14,15 and intron & \\
\hline C7R11 & GCAGAACAGGCTTGGTTGGGTGGGC & 14,15 & 759 \\
\hline C7F12 & AACCATGGGAAAAACAGGCAAAGGG & Exon $16-18$ and intron & \\
\hline C7R12 & CAGAGAGACACACAGGTGGGCGGAG & 16,17 & 763 \\
\hline
\end{tabular}

Genotyping was performed by direct sequencing using an $\mathrm{ABI} 3730 \mathrm{XL}$ sequencer. The gene-specific primer closest to the SNP was used to resequence the PCR products from resistant and susceptible populations. In the validation set, approximately $5 \%$ of the samples were sequenced again and the concordance was found to be $100 \%$. Prior to sequencing, fragment identity was checked by separation on $2 \%$ agarose gels. PCR products were then purified using a Gel Extraction kit (Tiangen, Bejing, China), and the derived sequences were analyzed and manually checked using Sequencher 4.0.

\section{Statistical analyses}

Allele and genotype frequencies of the C7 polymorphism between the susceptible and resistant group were compared using the Statistical Analysis System (SAS) version 9.1 (SAS Institute, Inc., Cary, NC, USA). Linkage disequilibrium between all pairs of biallelic loci was examined using HAPLOVIEW 4.1 (Barrett et al., 2005). Permutation tests were performed to assess the extent of association of individual SNPs and haplotype blocks. For association analyses, haplotypes were obtained using PHASE 2.1.1 (Stephens et al., 2001), applying the algorithm 5 times for each set of SNPs on fish with full genotypic data. Odds ratios and 95\% confidence intervals were computed to assess the odds of the associated haplotype. Statistical significance was considered when $\mathrm{P}<0.05$.

\section{RESULTS}

\section{Bacterial infection of grass carp}

During the course of infection, the fish that died because of infection (68.2\%) displayed a wide range survival times (1-16 days). The 186 juveniles that died in the first 12 days were considered susceptible individuals. Daily mortality diminished to nearly 0 by the end of this trial, 
indicating that the survivors were disease-tolerant. At the end of the 21-day trial, a total of 191 (31.8\%) juveniles survived and considered resistant. No fish mortality was observed in the control group.

\section{Identification of SNPs in the C7 gene}

A total of $7826 \mathrm{bp}$ of the grass carp $\mathrm{C} 7$ ( $\mathrm{gcC} 7$ ) gene, including the coding region, $5^{\prime}$ and 3'-untranslated regions, intronic regions, and promoter sequence (GenBank Accession No. JN710442), were sequenced from 30 fish of different populations. After sequence analysis, we identified 6 SNPs (-1575 A>C, -688 T>C, -266 A>C, $425 \mathrm{C}>\mathrm{T}, 803 \mathrm{~A}>\mathrm{G}, 950 \mathrm{~A}>\mathrm{T}$ ) (Figure 1), of which an SNP was positioned in promoter region of the gene, 4 were located in the non-coding introns, and 1 was found in the coding region. The SNP 425 C>T identified in the coding exon was a synonymous substitution in the 4 th exon.

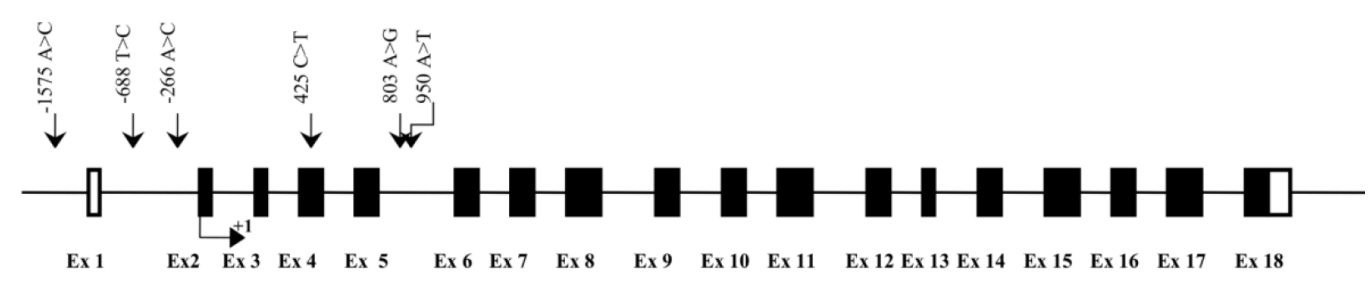

Figure 1. Schematic gene map and SNPs in the C7 gene. The corresponding positions and nucleotides are marked.

\section{Associations between SNPs and disease resistance}

All 6 SNPs were successfully genotyped, and the genotype and allele frequencies of the $\mathrm{C} 7$ gene polymorphisms in resistant and susceptible populations are shown in Table 2. Statistical analysis showed that SNP $425 \mathrm{C}>\mathrm{T}$ was associated with the incidence of hemorrhagic septicemia ( $P=0.045$ for genotype and $P=0.028$ for allele). In the susceptible group, the CC, CT, and TT genotype frequencies were $59.1,27.4$, and $13.4 \%$, respectively, while the corresponding frequency distributions in the resistant group were $46.6,37.7$, and $15.7 \%$ respectively, which was significantly different from the susceptible fish $(P<0.05)$. The allele distribution between the 2 groups was significantly different $(P<0.05)$. There were no significant differences in genotypic or allelic frequencies between susceptible and resistant groups for the remaining SNPs $(P>0.05)$.

\section{Linkage disequilibrium and haplotype analysis}

The extent of linkage disequilibrium was assessed between the 6 SNPs in $\mathrm{C} 7$ using the Haploview version 4.0 software. The SNPs $-1575 \mathrm{~A}>\mathrm{C},-688 \mathrm{~T}>\mathrm{C}$, and $-266 \mathrm{~A}>\mathrm{C}$ were highly linked $\left(r^{2}>0.85\right)$ (Figure 2). These 3 SNPs were used to generate haplotypes in susceptible and resistant groups. The haplotype ACT was observed with higher frequency in the 2 groups. Table 3 shows the haplotype frequencies for 4 haplotypes with a frequency $>5 \%$ in susceptible and resistant groups and their association with incidence of hemorrhagic septicemia. Statistical analysis revealed that no haplotypes were associated with hemorrhagic septicemia complex $(P>0.05)$ (Table 3). 
Table 2. Distributions of gcC7 gene polymorphisms in susceptible and resistant groups.

\begin{tabular}{|c|c|c|c|c|c|c|c|c|}
\hline Locus & Genotype & Susceptible No. (\%) & Resistant No. (\%) & $\chi^{2}(\mathrm{P})$ & Allele & Susceptible No. (\%) & Resistant No. (\%) & $\chi^{2}(\mathrm{P})$ \\
\hline \multirow[t]{3}{*}{$-1575 A>C$} & AA & 77 (41.4) & $92(48.2)$ & 1.7525 & A & $236(63.4)$ & $258(67.5)$ & 1.4012 \\
\hline & $A C$ & $82(44.1)$ & 74 (38.7) & $(0.416)$ & C & $136(36.6)$ & $124(32.5)$ & $(0.236)$ \\
\hline & $\mathrm{CC}$ & 27 (14.5) & 25 (13.1) & & & & & \\
\hline \multirow[t]{3}{*}{$-688 \mathrm{~T}>\mathrm{C}$} & TT & 46 (24.7) & 38 (19.9) & 1.3737 & $T$ & $176(46.1)$ & $165(43.2)$ & 1.2902 \\
\hline & TC & $84(45.2)$ & $89(46.6)$ & $(0.503)$ & $\mathrm{C}$ & $196(53.9)$ & $217(56.8)$ & $(0.256)$ \\
\hline & $\mathrm{CC}$ & 56 (30.1) & 64 (33.5) & & & & & \\
\hline \multirow[t]{3}{*}{$-266 \mathrm{~A}>\mathrm{C}$} & AA & $133(71.5)$ & $132(69.1)$ & 0.2599 & A & 309 (83.1) & $312(81.7)$ & 0.2503 \\
\hline & $A C$ & $43(23.1)$ & $48(25.1)$ & $(0.878)$ & C & $63(16.9)$ & 70 (18.3) & $(0.617)$ \\
\hline & $\mathrm{CC}$ & $10(5.4)$ & $11(5.8)$ & & & & & \\
\hline \multirow[t]{3}{*}{$425 \mathrm{C}>\mathrm{T}$} & $\mathrm{CC}$ & $110(59.1)$ & $89(46.6)$ & 6.1908 & C & $271(72.8)$ & $250(65.4)$ & 4.8391 \\
\hline & CT & $51(27.4)$ & $72(37.7)$ & $(0.045)$ & $T$ & $101(27.2)$ & $132(34.5)$ & $(0.028)$ \\
\hline & TT & 25 (13.4) & 30 (15.7) & & & & & \\
\hline \multirow[t]{3}{*}{$803 A>G$} & AA & $114(61.3)$ & $123(64.4)$ & 1.0617 & A & $289(77.7)$ & $300(78.5)$ & 0.0789 \\
\hline & $A G$ & $61(32.8)$ & $54(28.3)$ & $(0.588)$ & G & $83(22.3)$ & $82(21.5)$ & $(0.779)$ \\
\hline & GG & $11(5.9)$ & $14(7.3)$ & & & & & \\
\hline \multirow[t]{3}{*}{$950 \mathrm{~A}>\mathrm{T}$} & AA & $12(6.5)$ & $13(6.8)$ & 1.4125 & A & $83(22.3)$ & 76 (19.9) & 0.6614 \\
\hline & AT & 59 (31.7) & $50(26.2)$ & $(0.493)$ & $T$ & $289(77.7)$ & $306(80.1)$ & $(0.416)$ \\
\hline & TT & $115(61.8)$ & $128(67.0)$ & & & & & \\
\hline
\end{tabular}

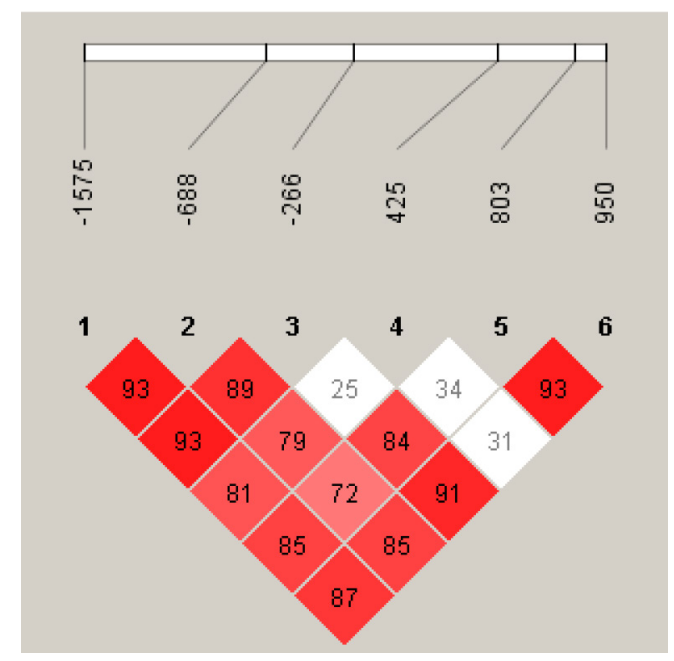

Figure 2. An LD map showing the pairwise LD between the SNPs in the $C 7$ gene. The values inside the squares indicate the D' values of the 2 SNPs.

Table 3. Haplotype analysis of gcC7 SNPs including marker $-1575 \mathrm{~A}>\mathrm{C},-688 \mathrm{~T}>\mathrm{C}$, and $-266 \mathrm{~A}>\mathrm{C}$ with hemorrhagic septicemia.

\begin{tabular}{l|c|c|c|c}
\hline Haplotype & Susceptible No (\%) & Resistant No (\%) & P value & OR (95\%Cl) \\
\hline ACT & 31.7 & 36.9 & 0.466 & $1.171(0.76-1.79)$ \\
\hline CTT & 33.3 & 30.7 & 0.494 & $1.151(0.77-1.73)$ \\
\hline ACA & 19.4 & 19.3 & 0.233 & $1.199(0.78-1.834)$ \\
\hline ATT & 10.7 & 12.1 & 0.408 & $0.915(0.563-1.487)$ \\
\hline
\end{tabular}

\section{DISCUSSION}

Hemorrhagic septicemia is responsible for annual economic losses of millions of USD to the freshwater aquaculture industry in the USA, China, and other countries (da Silva et al., 2012; Zheng et al., 2012). Since its recognition as a causative agent of bacterial hemorrhagic septicemia, 
the motile aeromonads have been considered pathogens. Holliman (1993) found that $A$. hydrophila was the most virulent among the motile aeromonads strains for fish (Holliman, 1993). The fish in the resource population were challenged with this bacterium; before death, some fish showed hemorrhage in the fin base, dark skin, and erratic swimming. While the dead fish showed signs of bacterial infection, the surviving fish were not assumed free of infection. Particularly, younger infected fish do not manifest any noticeable symptoms during the subclinical stages of infection. Thus, we monitored mortality of fish for 21 days. The fish used in this study were from our breed farms that had not been exposed to $A$. hydrophila, rather than having enhanced genetic resistance. Therefore, in our study, the challenged fish were healthy.

C7 is a critical component of the terminal pathway of activation; its main function is to contribute to the formation of MAC and cytolytically inactive SC5b-9 involved in the host defense against pathogens and in the promotion of inflammation. C7 is primarily synthesized extrahepatically at the site of inflammation by granulocytes (Høgåsen et al., 1995) and endothelial cells (Tedesco et al., 1997), thereby modulating lytic or sublytic membrane attack (Würzner, 2000; Langeggen et al., 2000). A number of studies have reported that variations in C7 play an important role in the resistance to a variety of diseases in humans (Kallio et al., 2009; Barroso et al., 2010). To date, at least 25 different sequence variants have been reported that can lead to $\mathrm{C} 7$ deficiency (RameixWelti et al., 2007). Deficiency in C7 increases the susceptibility to bacterial infection. Therefore, grass carp $\mathrm{C} 7$ was selected as a promising candidate gene for SNP detection. In this study, 3 populations were used to detect SNPs, the genetic distances between which were large. Only 1 SNP in an exon and 1 SNP in the promoter region were identified. The human $\mathrm{C} 7$ gene is rich in polymorphisms. Thus, the 30 fish used to detect SNPs have high genetic diversity, and it is unlikely that all SNPs segregated in the grass carp population were identified.

Genetic associations are useful for fine mapping of disease association and for determining whether effect sizes of the associated alleles are similar or different across populations. There have been no studies examining the association between polymorphism in $\mathrm{C} 7$ and disease resistance in fish. In this study, all 6 SNPs were analyzed for their associations with A. hydrophila resistance in grass carp. Statistical analysis revealed that only SNP $425 \mathrm{C}>\mathrm{T}$ was associated with resistance to A. hydrophila both on the genotype $(P=0.045)$ and allele $(P=0.028)$ levels. We found that the 425T allele showed higher resistance to $A$. hydrophila than the $425 \mathrm{C}$ allele (Table 2). SNP $425 \mathrm{C}>\mathrm{T}$ is a synonymous mutation that does not cause changes in amino acid sequences. Its association with disease resistance may results from its linkage to a non-synonymous mutation nearby affecting the function of $\mathrm{C} 7$ and host defense. In an early challenge experiment, significant changes in $\mathrm{C} 7$ transcript expression were detected following A. hydrophila infection (Shen et al., 2012). In humans, $\mathrm{C} 7$ deficiency is an autosomal recessive disorder that is well known to be associated with increased susceptibility to meningococcal infection, particularly Neisseria meningitis (Nürnberger et al., 1989; Barroso et al., 2010). In addition to meningitis, some patients diagnosed with $\mathrm{C} 7$ deficiency also presented with Sjögren-Larsson syndrome, CREST-like syndrome, chronic nephritis, or persistent hematuria (Nürnberger et al., 1989; Segurado et al., 1992). Linkage mapping analysis showed that grass carp C7 was mapped to linkage group 3 using this SNP (Shen YB, Xu XY and Li JL, unpublished results), but a genome-wide scan for resistance to $A$. hydrophila infection in grass carp has not been carried out. Therefore, the 425T allele may be associated with disease resistance. Further studies are needed to determine whether $\mathrm{C} 7$ is associated with resistance to $A$. hydrophila.

In conclusion, 6 SNPs were identified in the complement component $\mathrm{C} 7$ of grass carp, and 1 synonymous SNP $425 \mathrm{C}>\mathrm{T}$ was found to be significantly associated with resistance to 
A. hydrophila in grass carp, suggesting that the $\mathrm{C} 7$ gene plays an important role in resistance to bacterial pathogens and that SNP $425 \mathrm{C}>\mathrm{T}$ markers can be used to select grass carp that are resistant to hemorrhagic septicemia. Additional studies should verify these findings through population-based prospective studies with fish from different geographical populations.

\section{ACKNOWLEDGMENTS}

Research supported by the Earmarked Fund for the National Key Technology R\&D Program (\#2012BAD26B02), the China Agriculture Research System (\#CARS-46-04), the Agricultural Seed Development Program of Shanghai City (\#2012NY10), and the Shanghai Ocean University Doctoral Research Foundation. The authors were supported by the Shanghai Universities Firstclass Disciplines Project of Fisheries.

\section{REFERENCES}

Barrett JC, Fry B, Maller J and Daly MJ (2005). Haploview: analysis and visualization of LD and haplotype maps. Bioinformatics 21: 263-265. http://dx.doi.org/10.1093/bioinformatics/bth457

Barroso S, López-Trascasa M, Merino D, Alvarez AJ, et al. (2010). C7 deficiency and meningococcal infection susceptibility in two spanish families. Scand. J. Immunol. 72: 38-43.

Cai R (1991). Development History of Freshwater Culture in China. China Press of Science \& Technology, Beijing, China.

Cao H, He S, Wang H, Hou S, et al. (2012). Bdellovibrios, potential biocontrol bacteria against pathogenic Aeromonas hydrophila. Vet. Microbiol. 154: 413-418. http://dx.doi.org/10.1016/j.vetmic.2011.07.032

Carroll MV and Sim RB (2011). Complement in health and disease. Adv. Drug Deliv. Rev. 63: 965-975. http://dx.doi. org/10.1016/j.addr.2011.06.005

Crumlish M, Thanh PC, Koesling J, Tung VT, et al. (2010). Experimental challenge studies in Vietnamese catfish, Pangasianodon hypophthalmus (Sauvage), exposed to Edwardsiella ictaluri and Aeromonas hydrophila. J. Fish Dis. 33: 717-722. http:// dx.doi.org/10.1111/j.1365-2761.2010.01173.x

da Silva BC, Mourino JLP, Vieira FN, Jatoba A, et al. (2012). Haemorrhagic septicaemia in the hybrid surubim (Pseudoplatystoma corruscans x Pseudoplatystoma fasciatum) caused by Aeromonas hydrophila. Aquacult. Res. 43: 908-916. http://dx.doi. org/10.1111/j.1365-2109.2011.02905.x

DiScipio RG and Gagnon J (1982). Characterization of human complement components C6 and C7. Mol. Immunol. 19: 14251431. http://dx.doi.org/10.1016/0161-5890(82)90189-4

DiScipio RG, Chakravarti DN, Muller-Eberhard HJ and Fey GH (1988). The structure of human complement component C7 and the C5b-7 complex. J. Biol. Chem. 263: 549-560.

FAO (2012). The State of World Fisheries and Aquaculture 2012, Rome.

Hobart MJ, Fernie BA and DiScipio RG (1995). Structure of the human C7 gene and comparison with the C6, C8A, C8B, and C9 genes. J. Immunol. 154: 5188-5194.

Høgåsen AK, Würzner R, Abrahamsen TG and Dierich MP (1995). Human polymorphonuclear leukocytes store large amounts of terminal complement components C7 and C6, which may be released on stimulation. J. Immunol. 154: 4734-4740.

Holland MC and Lambris JD (2002). The complement system in teleosts. Fish Shellfish Immunol. 12: 399-420. http://dx.doi. org/10.1006/fsim.2001.0408

Holliman A (1993) The veterinary approach to trout. In: Aquaculture for Veterinarians: Fish Husbandry and Medicine(Brown L, ed.), Pergamon Press, Oxford, UK, 223-247.

Langeggen H, Pausa M, Johnson E, Casarsa C, et al. (2000). The endothelium is an extrahepatic site of synthesis of the seventh component of the complement system. Clin. Exp. Immunol. 121: 69-76. http://dx.doi.org/10.1046/j.1365$\underline{2249.2000 .01238 . x}$

Lian LH, Ching AS, Chong ZY and Chua KH (2012). Complement components 2 and 7 (C2 and C7) gene polymorphisms are not major risk factors for SLE susceptibility in the Malaysian population. Rheumatol. Int. 32: 3665-3668. http://dx.doi. org/10.1007/s00296-011-2070-0

Liu F, Xia J-H, Bai Z-Y, Fu J-J, et al. (2009). High genetic diversity and substantial population differentiation in grass carp (Ctenopharyngodon idella) revealed by microsatellite analysis. Aquaculture 297: 51-56. http://dx.doi.org/10.1016/j. aquaculture.2009.09.008 
Kallio SP, Jakkula E, Purcell S, Suvela M, et al. (2009). Use of a genetic isolate to identify rare disease variants: C7 on $5 p$ associated with MS. Hum. Mol. Genet. 18: 1670-1683. http://dx.doi.org/10.1093/hmg/ddp073

Mahapatra KD, Gjerde B, Sahoo P, Saha J, et al. (2008). Genetic variations in survival of rohu carp (Labeo rohita, Hamilton) after Aeromonas hydrophila infection in challenge tests. Aquaculture 279: 29-34. http://dx.doi.org/10.1016/j. aquaculture.2008.03.054

Nishimukai H, Nakanishi I, Takeuchi Y, Sumiyoshi R, et al. (1989). Complement C6 and C7 polymorphisms in Japanese patients with chronic glomerulonephritis. Hum. Hered. 39: 150-155. http://dx.doi.org/10.1159/000153851

Nürnberger W, Pietsch H, Seger R, Bufon T, et al. (1989). Familial deficiency of the seventh component of complement associated with recurrent meningococcal infections. Eur. J. Pediatr. 148: 758-760. http://dx.doi.org/10.1007/BF00443104

Ødegård J, Olesen I, Dixon P, Jeney Z, et al. (2010). Genetic analysis of common carp (Cyprinus carpio) strains. II: Resistance to koi herpesvirus and Aeromonas hydrophila and their relationship with pond survival. Aquaculture 304: 7-13. http:// dx.doi.org/10.1016/j.aquaculture.2010.03.017

Rameix-Welti MA, Régnier CH, Bienaimé F, Blouin J, et al. (2007). Hereditary complement C7 deficiency in nine families: subtotal C7 deficiency revisited. Eur. J. Immunol. 37: 1377-1385. http://dx.doi.org/10.1002/eji.200636812

Segurado OG, Arnaiz-Villena AA, Iglesias-Casarrubios P, Martinez-Laso J, et al. (1992). Combined total deficiency of C7 and C4B with systemic lupus erythematosus (SLE). Clin. Exp. Immunol. 87: 410-414. http://dx.doi.org/10.1111/j.1365-2249.1992. $\underline{\mathrm{tb} 03011 . x}$

Shen Y, Zhang J, Xu X, Fu J, et al. (2012). Expression of complement component C7 and involvement in innate immune responses to bacteria in grass carp. Fish Shellfish Immunol. 33: 448-454. http://dx.doi.org/10.1016/j.fsi.2012.05.016

Shen Y, Zhang J, Xu X, Fu J, et al. (2013). A new haplotype variability in complement C6 is marginally associated with resistance to Aeromonas hydrophila in grass carp. Fish Shellfish Immunol. 34: 1360-1365. http://dx.doi.org/10.1016/j. fsi.2013.02.011

Stephens M, Smith NJ and Donnelly P (2001). A new statistical method for haplotype reconstruction from population data. Am. J. Hum. Genet. 68: 978-989. http://dx.doi.org/10.1086/319501

Tedesco F, Pausa M, Nardon E, Introna M, et al. (1997). The cytolytically inactive terminal complement complex activates endothelial cells to express adhesion molecules and tissue factor procoagulant activity. J. Exp. Med. 185: 1619-1627. http://dx.doi.org/10.1084/jem.185.9.1619

Würzner R (2000). Modulation of complement membrane attack by local C7 synthesis. Clin. Exp. Immunol. 121: 8-10. http:// dx.doi.org/10.1046/j.1365-2249.2000.01263.x

Zhang YL, Ong CT and Leung KY (2000). Molecular analysis of genetic differences between virulent and avirulent strains of Aeromonas hydrophila isolated from diseased fish. Microbiology 146: 999-1009. http://dx.doi.org/10.1099/00221287-1464-999

Zheng W, Cao H and Yang X (2012). Grass carp (Ctenopharyngodon idellus) infected with multiple strains of Aeromonas hydrophila. Afr. J. Microbiol. Res. 6: 4512-4520. 